\title{
Safe and effective percutaneous ethanol injection therapy of 200 thyroid cysts
}

\author{
Milan Halenka, David Karasek, Jan Schovanek, Zdenek Frysak
}

\begin{abstract}
Introduction. Ultrasound-guided percutaneous ethanol injection therapy (US-PEIT) is a minimally invasive procedure that may be performed as an alternative to surgery for the treatment of recurrent symptomatic thyroid cysts for which simple aspiration failed. The present study aimed at assessing US-PEIT in a large cohort of patients, identifying factors influencing treatment outcome.

Methods. Retrospective analysis of 193 patients with 200 thyroid cysts who underwent US-PEIT in 2004-2018.

Results. The initial median cyst volume was $8.5 \mathrm{~mL}$ [5.5-16.0]; median final volume at 12 months after the completion of therapy was $0.5 \mathrm{~mL}$ [0.2-1.3]. A Volume Reduction Rate (VRR) of 95.0\% [86.7-98.0] was achieved. For successful USPEIT, relatively small total amount of ethanol was needed, on average corresponding to $20.0 \%$ [16.7-28.6] of the initial cyst volume. VRR positively correlated with the initial cyst volume and negatively with the presence of complex cyst. Multiple regression analysis showed the presence of complex cyst as an independent predictor of treatment efficacy. Conclusion. US-PEIT of thyroid cysts of all sizes was very successful with using total amounts of ethanol, corresponding to $\approx 20 \%$ of the initial cyst volume.
\end{abstract}

Key words: thyroid cyst, ultrasound-guided percutaneous ethanol injection therapy, volume reduction rate

Received: January 3, 2019; Accepted with revision: February 28, 2019; Available online: March, 29, 2019 https://doi.org/10.5507/bp.2019.007

(c) 2020 The Authors; https://creativecommons.org/licenses/by/4.0/

Department of Internal Medicine III - Nephrology, Rheumatology and Endocrinology

Faculty of Medicine and Dentistry, Palacky University Olomouc and University Hospital Olomouc, Czech Republic

Corresponding author: Milan Halenka, e-mail: milan.halenka@fnol.cz

\section{INTRODUCTION}

According to the 2015 ATA Management Guidelines for Adult Patients with Thyroid Nodules and Differentiated Thyroid Cancer, the prevalence of palpable nodules is $5 \%$ in females and $1 \%$ in males living in iodine-sufficient parts of the world. High-resolution ultrasound is able to detect thyroid nodules in 19-68\% of a random population, with higher frequencies in females and the elderly ${ }^{1}$. Cystic nodules develop due to hemorrhage or degenerative changes in originally solid nodules. Primary cysts are rare, accounting for approximately $1 \%$ of all cysts ${ }^{2}$. Complex nodules with cystic component account for $15-37 \%$ of all operated nodules ${ }^{3}$. Based on ultrasound scans, predominantly cystic nodules (complex cysts) are those with the cystic portion accounting for $50-90 \%$ of the volume and pure cysts are nodules with the cystic portion accounting for $>90 \%$ of the nodule volume ${ }^{4}$. Approximately $15-25 \%$ of nodules are predominantly cystic or cystic ${ }^{5}$.

The indications for therapy are compressive symptoms or cosmetics complaints. After simple aspiration of the cystic cavity, recurrence is observed in up to $80 \%$ of cases, depending on the volume and contents ${ }^{5}$. The standard treatment approach of recurrent cysts represents surgery, either total thyroidectomy or lobectomy. Alternatively, ultrasound-guided percutaneous ethanol injection therapy (US-PEIT) with 96-99\% ethanol may be used. Ethanol causes coagulative necrosis in the cyst wall. Subsequently, reactive fibrosis and cyst shrinkage occurs ${ }^{6,7}$. This meth- od is suitable for patients with a large, solitary cyst or a dominant cyst in a multinodular goiter (other unsuspected nodules less than $1 \mathrm{~cm}$ ). US-PEIT is performed in cystic lesions with the cystic portion accounting for $>60 \%$ of the nodule volume ${ }^{6}$.

US-PEIT is considered therapeutically successful if the cyst is reduced by $>50 \%$ of its initial volume. In published cohorts, the success rate ranges from $68 \%$ to $100 \%$ (ref. $^{6,8}$ ). After 20 years of experience, in 2010, the approach was approved as a full-fledged method in the Medical Guidelines for Clinical Practice for the Diagnosis and Management of Thyroid Nodules ${ }^{9,10}$.

We aimed this study at assessing US-PEIT in a larger cohort $(n=200)$ including large thyroid cysts and identifying factors influencing treatment outcome.

\section{METHODS AND PATIENTS}

All patients were provided with explanation of the procedure and signed informed consent forms approved by the University Hospital Olomouc Ethics Committee. The cohort comprised 193 patients (150 females and 43 males) with 200 thyroid cysts (seven female patient having 2 cysts) who were selected for US-PEIT between 2004 and 2018 and completed a follow-up of 12 months. US-PEIT was either performed in patients at increased surgical risk or those refusing surgery; all cysts were symptomatic or recurred after previous simple aspiration (1-4 times). In all 
cases, cytology examination was carried out, with benign results being an inclusion criterion (pure cyst Bethesda I and complex cyst Bethesda II). All patients had normal baseline TSH and fT4 levels. The cohort excluded 28/228 patients, when simple aspiration was enough to treat the cyst and over 12 months no recurrence occurred.

For statistical analysis, the cohort was divided into subgroups based on the cyst volume and character of the cystic component. Three size groups were defined as follows: small cysts (3-10 mL; $\mathrm{n}=112)$, medium-sized cysts (11-30 mL; $n=67)$ and large cysts $(\geq 31 \mathrm{~mL} ; n=21$; including 3 extremely large cysts $>100 \mathrm{~mL}$ ). Based on their character, two types of cysts were distinguished, pure and complex. On US scan, a pure cyst $(n=49)$ had anechoic content, smooth internal wall, no septa and a cystic component accounting for more than $90 \%$ of the cyst volume (Fig. 1a, b); the drained fluid was clear or pale yellow, without detritus. A complex cyst $(n=151)$ had anechoic or flocculated content, roughened wall or a focally preserved solid part of the nodule and a cystic component accounting for $60-90 \%$ of the cyst volume (Fig. 2a, b). The cystic cavity was either septated of irregular shape or multilocular with one dominant cyst and several tiny ones; the drained fluid was brown, viscous-to-gelatinous and often containing detritus.

To assess the effect of US-PEIT, the Volume Reduction Rate (VRR) was calculated as follows: VRR (\%) = initial cyst volume - final cyst volume / initial cyst volume $\times$ 100 (ref. ${ }^{11}$ ). The therapeutic goal was a reduction in cyst volume of $>50 \%$ and disappearance of the cystic cavity. Complete disappearance of the cystic cavity was the goal in all pure cysts. In case of complex (septated and multilocular) cysts, tiny residual cavities sized less than $5 \mathrm{~mm}$ could have remained with no ethanol penetrating inside. In case of cystic cavity recurrence during the 12 months follow-up from the completion of therapy an additional US-PEIT would be performed and follow-up would be rescheduled.

Both US scans and US-PEIT were carried out using the Philips Sonos 5500 and, from 2011, Philips iU22 with $10-\mathrm{MHz}$ probe. For the cyst aspiration, $20-\mathrm{mL}$ syringes and 20-gauge or, in case of highly viscous cysts, 18-gauge needles were used. In all patients, a non-aspiration approach to US-PEIT was used, that is, the instilled ethanol (96\%) was left in the cyst ${ }^{7}$. The procedure was performed without local anesthesia ${ }^{11}$. In patients receiving long-term anticoagulation therapy with warfarin, the drug was discontinued 5 days before US-PEIT and replaced with lowdose low-molecular-weight heparin. Direct anticoagulants were discontinued $48 \mathrm{~h}$ before the procedure. The treatment was resumed $24 \mathrm{~h}$ after the procedure. Antiplatelet therapy was not discontinued.

Patients were seen after 1 month. If US scan revealed recurrent fluid present in the cystic cavity $(>1 \mathrm{~mL})$, it was drained and the second US-PEIT session was performed ${ }^{5}$. If the first procedure was successful, that is, the cyst was not filled again and only solid, slightly hyperechoic contents were observed, regular US check-ups followed after 3, 6 and 12 months. If the second or third sessions were needed, the first check-up was one month later and then the same follow-up pattern was used. In case of very large cysts ( 8 cysts $>60 \mathrm{~mL}$ ), the intervals between US-PEIT sessions were shortened to 14 days at the beginning of the treatment.

The amounts of ethanol used during the first session were 1-2 $\mathrm{mL}$ and 3-5 mL for small and medium-sized cysts, respectively. For large cyst the initial volume of ethanol were 5-8 $\mathrm{mL}$ and for three extremely large cysts (>100 mL), the maximum single dose was $10 \mathrm{~mL}$ (ref. ${ }^{5}$ ). During the other sessions, the amount of ethanol was equal to $20 \%$ of the residual fluid volume.

All analyzed parameters were not normally distributed according to Shapiro-Wilk's test. Therefore, the median and interquartile range ( 25 th and 75 th percentile) were used to express the values. To compare changes at 1, 3, 6 and 12 months after US-PEIT, Friedman's ANOVA with the Wilcoxon test were used. To determine possible differences in the subgroups, the Mann-Whitney U test and Kruskal-Wallis test were performed for two and three subgroups, respectively. Spearman's correlation analysis was used to assess relationships between parameters and linear regression analysis was performed to determine independent predictors of treatment. The level of statistical significance was set at $P<0.05$.

\section{RESULTS}

In all 193 patients with 200 cysts, US-PEIT was successful and the therapeutic goal was achieved. At 12 months, the VRR was 95.0\% [86.7-98.0] for the entire cohort, 97.5\% [95.4-98.7] for pure cysts and 92.3\% [83.396.7] for complex cysts (for details see Table 1). No patient was indicated for surgery due to method failure.

The patients' mean age was 49.0 [38.0-67.0] years. The age characteristics of the sample were as follows: the youngest patients - a 17-year-old female and a 22-year-old male; the oldest patients - two 83-year-old females and a 79-year-old male.

Solitary cysts were present in 104 patients. Dominant cysts in a multinodular goiter were found in 96 patients; of those, seven female patients had two cysts in both thyroid lobes (Fig. 3a, b).

The initial cyst volume ranged between $3.0 \mathrm{~mL}$ and $170.0 \mathrm{~mL}$. Number of US-PEIT sessions were as follows: $1 \times$ in 101 cysts, $2 \times$ in 69 cysts, $3 \times$ in 22 cysts, $4 \times$ in 6 cysts, $5 \times$ in 1 cyst and $9 \times$ in 1 giant multilocular cyst. The mean number of US-PEIT sessions was $1.72 \pm 0.97$. The total amount of instilled ethanol was 1-60 mL (median [interquartile range] $=2.0[1.0-3.0] \mathrm{mL})$, corresponding to $4.2-66.7 \%$ (median [interquartile range] $=20.0$ [16.7$28.6] \%$ ) of the initial cyst volume. The detailed results for the entire cohort and subgroups by cyst size and type are summarized in Table 1. In both the entire cohort and individual subgroups, the initial cyst volume was significantly reduced as could be seen from the final cyst volume at 12 months after US-PEIT was completed $(P<0.001)$ and the VRR was significantly increasing during the regular check-ups at 1, 3, 6 and 12 months $P<0.05)$. For the entire cohort, significant $(P<0.05)$ negative correlations were 


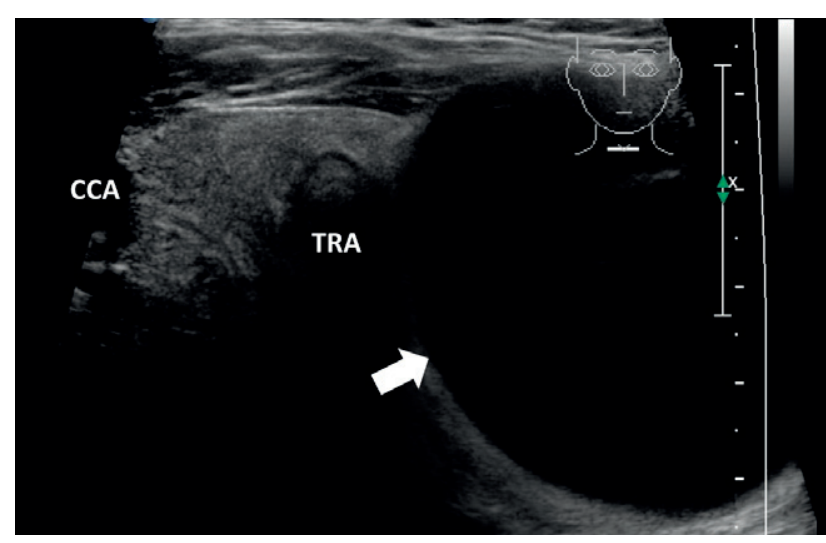

Fig. 1a. An 81-year-old woman with a one month palpable resistance on the neck.

US scan prior to PEIT revealed solitary large pure cyst (full arrow), size $66 \times 63 \times 44 \mathrm{~mm}$ and volume $96 \mathrm{~mL}$ occupying whole left lobe: smooth wall; anechoic contents; evacuation of yellow liquid; transverse. CCA - common carotid artery, TRA - trachea

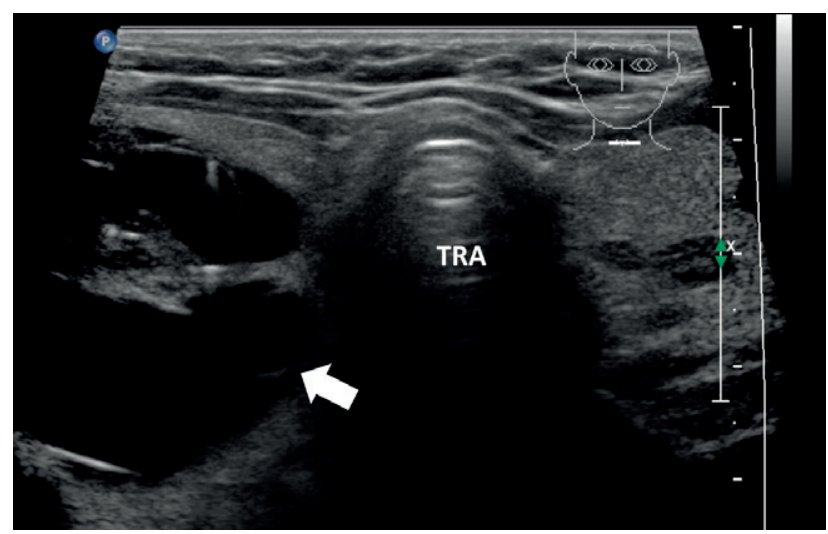

Fig. 2a. A 53-year-old woman with two years palpable resistance on the neck.

US scan prior to PEIT showed multinodular goiter with dominant large complex septated cyst (full arrow), size $58 \times 42 \times 27$ $\mathrm{mm}$ and volume $35 \mathrm{~mL}$ in the right lobe (fluid recurrence after three evacuations of brownish liquid): hyperechoic focally thick wall, anechoic contents with one tiny colloid clot and "comet tail", thick transverse septum and another thin septa et periphery, tiny complex nodules in the left lobe; transverse.

found between the VRR at 12 months and with the complex type of cyst $(\rho=-0.37, P<0.05)$, number of US-PEIT sessions $(\rho=-0.24, P<0.05)$ and amount of instilled ethanol $(\rho=-0.21, P<0.05)$. No significant correlation were found with age and the initial cyst volume. Multivariate regression analysis also showed the presence of a complex cyst (beta $=-0.30, P<0.001$ ), number of US-PEIT sessions (beta $=0.84, P<0.001$ ), and amount of instilled ethanol (beta $=-0.32, P<0.001$ ), to be independent predictors for the VRR at 12 months.

When considering the cyst size, statistical differences were found in the success rate of US-PEIT and amount of instilled ethanol (larger cysts required higher rate of USPEIT and amount of instilled ethanol, although the ratio ethanol amount to initial cyst volume was significantly lower). VRR at all months was significantly higher in large

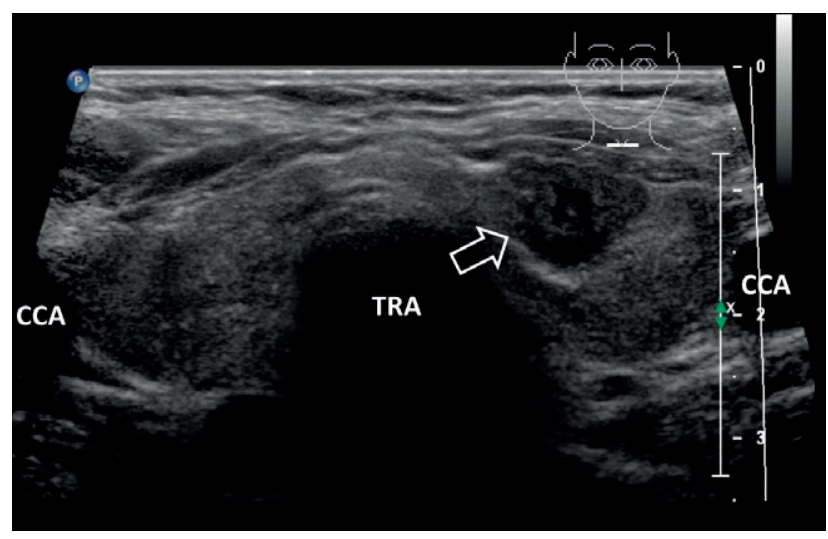

Fig. 1b. Twelve months post $3 \times$ PEIT.

small solid nodule (empty arrow), size $14 \times 11 \times 8 \mathrm{~mm}$ and volume $0.7 \mathrm{~mL}$ as residue of cyst: inhomogeneous structure, mostly isoechoic, focally hypoechoic areas, no recurrence of the liquid component; transverse.

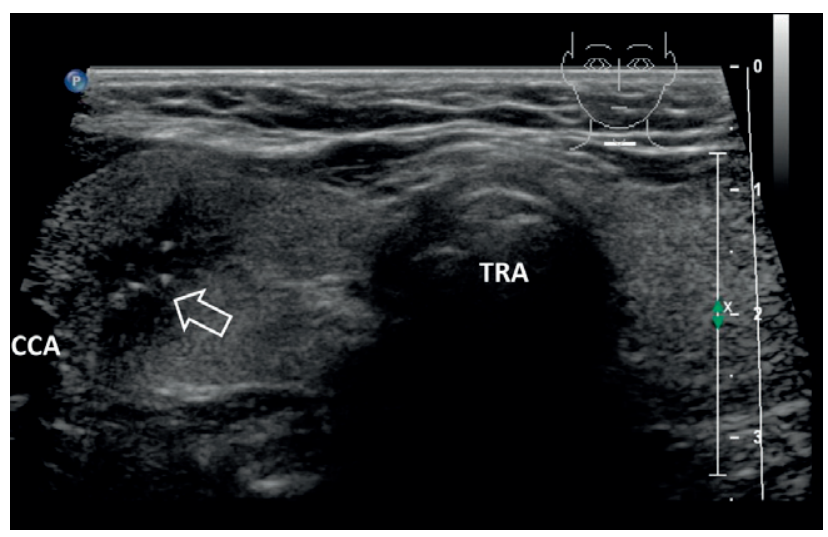

Fig. 2b. Twelve months post $3 \times$ PEIT.

small solid nodule (empty arrow), size $14 \times 11 \times 7 \mathrm{~mm}$ and volume $0.6 \mathrm{~mL}$ as residue of cyst: inhomogeneous structure, mostly hypoechoic, tiny punctuations of fibrosis, no recurrence of the liquid component; transverse.

cysts compared to small cysts although final cyst volume remained higher in large than in small cysts.

Comparison of complex and pure cysts showed that US-PEIT was more successful (according to VRR at all months) in pure cysts. Although less ethanol amount was used, fewer US-PEIT sessions and smaller amounts of ethanol relative to the initial cyst volumes were needed (see Table 1). Figure 4 shows the increase of VRR after repeated injection in pure and complex cysts.

In our study we observed only minor complications of the procedure; transient mild local pain was most frequently observed $(58 / 200, \approx 29 \%)$, usually disappearing within several hours but no later than three days after the procedure. Local anesthesia was not needed. Another typical complaint, particularly noted in elderly patients, was a short-lasting dizziness occurring immediately after 


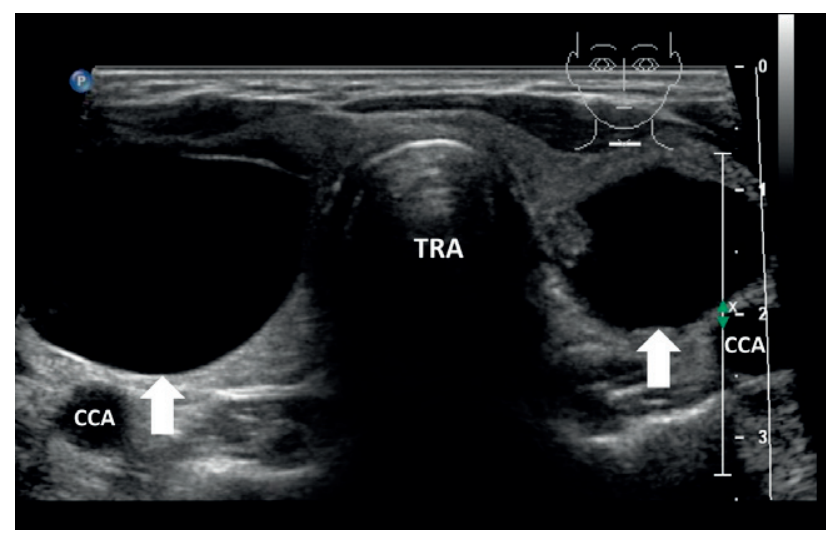

Fig. 3a. A 35-year-old woman with three years palpable resistance on the neck.

US scan prior to PEIT showed multinodular goiter with two complex cysts (full arrows), in the right lobe size $45 \times 35 \times 20$ $\mathrm{mm}$ and volume $16 \mathrm{~mL}$, in the left lobe size $35 \times 20 \times 15 \mathrm{~mm}$ and volume $6 \mathrm{~mL}$, (fluid recurrence after two resp. one evacuations of brownish liquid): smooth wall, only in the small cyst focally hyperechoic thick wall, anechoic contents; transverse.

the procedure; most likely resulting from the head being tilted back for about 10-15 min during the US examination and PEIT (dizziness is typically seen even after normal fine-needle aspiration biopsy). Two patients $(2 / 200,1 \%)$ with a large complex cysts experienced dysphonia lasting for 7-14 days after repeated US-PEIT, subsiding spontaneously without need for further specialized examination. No permanent dysphonia was noted. Also, no patient developed thyrotoxicosis or subsequent hypothyroidism. No life-threatening complications were observed in the patients undergoing US-PEIT.

\section{DISCUSSION}

It has been repeatedly confirmed, that a simple aspiration is mostly unsuccessful in treatment of thyroid cysts. The high recurrence rates from $58 \%$ to $80 \%$, depended on the initial cyst volume, density of the fluid and number of previous aspirations ${ }^{5,12}$. After a simple evacuation we registered even $\approx 88 \%$ of recurrence in $>3 \mathrm{~mL}$ cyst.

US-PEIT for thyroid cysts is a successful alternative to surgery. At 12 months after the completion of US-PEIT (a non-aspiration approach), the VRR was $95.0 \%$ for the entire cohort $(n=200)$, with no recurrence being observed. Presence of a complex cyst was an independent predictor of treatment efficacy. In the complex cyst we observed lower VRR particularly after the first ethanol injection; however after repeated US-PEIT the final success rate increased. During all the monitored months of follow up the VRR differed statistically significantly in between the pure and complex cysts (Fig. 4).

The superiority of US-PEIT over the simple cyst aspiration was demonstrated by Verde et al. in 1994 ( $n=10 / 10$, therapeutic success in $80 \%$ vs. $30 \%$ ) or by Valcavi and Frasoldati $(n=143 / 138$, therapeutic success in $85.6 \%$ vs. $7.3 \%$ ) in 2004 (ref. $^{13,14}$ ). The superiority of ethanol

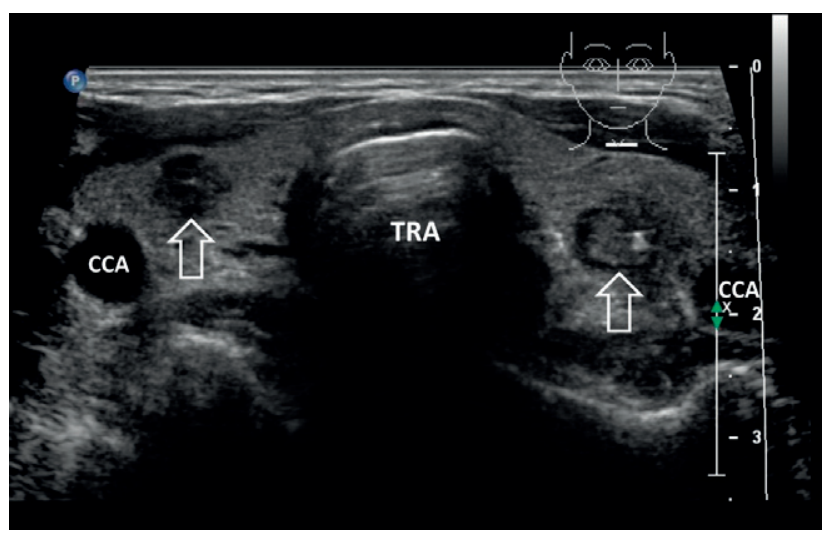

Fig. 3b. Twelve months post $2 \times$ simultaneous PEIT. small solid nodules (empty arrows) as residue of cysts, no recurrence of the liquid component: in the right lobe size $8 \times 6 \times$ $5 \mathrm{~mm}$ and volume $0.2 \mathrm{~mL}$, inhomogeneous structure, slightly hypoechoic, tiny punctuations of fibrosis and in the left lobe size $10 \times 7 \times 7 \mathrm{~mm}$ and volume $0.3 \mathrm{~mL}$, inhomogeneous structure, mostly isoechoic, tiny punctuations of fibrosis, anechoic "halo"; transverse.

over placebo (isotonic saline) in the treatment of cysts was reported by Bennedbaek and Hegedüs $(n=33 / 33$, therapeutic success in $82 \%$ vs. $48 \%$ ) or by Antonelli et al. ${ }^{5,15}(\mathrm{n}=26 / 44$, therapeutic success in $77 \%$ vs. $36 \%)$ or Zingrillo et al. or Del Prete et al. were successful at using US-PEIT for large cysts $\geq 40 \mathrm{~mL}(\mathrm{n}=20, \mathrm{n}=43, \mathrm{n}=98)$ (ref. ${ }^{16-18}$ ). In large cohorts reported in 2005 by Lee and Ahn $(n=432)$ and del Prete et al. $(n=98)$, the VRR ranged between $73 \%$ and $93 \%$ (ref. ${ }^{11,18}$ ). Kim DW et al. compared two approaches to US-PEIT, non-aspiration (leaving ethanol in the cyst; $n=30$ ) and aspiration (removal of ethanol from the cyst after $10 \mathrm{~min}$; $=30$ ). Both approaches were equally successful (96.7\% vs. $93.3 \%$ ) but there was a considerable difference in the total procedure time $(\approx 17$ vs. $\approx 31 \mathrm{~min}$ ). Moreover, the aspiration approach required another puncture of the cyst, resulting in increased risk of intracystic hemorrhage during the procedure (3\% vs. $23 \%$ ) ( ref. $^{7}$ ). These days, the aspiration approach is less common; it was initially developed to avoid undesirable ethanol leakage into the surroundings and further development of periglandular fibrosis that could impair potential surgery in case of US-PEIT failure and persistence of symptomatic cyst ${ }^{5,8,19,20}$.

Numerous studies concluded that the initial cyst volume was the only factor influencing the success of USPEIT. Cho et al. $(n=22)$, Lee and Ahn $(n=432)$ or Verde et al. $(n=32)$ reported significantly more successful treatment for larger cysts of $>10 \mathrm{~mL}$ (ref.6,12,14). Reverter et al. showed a higher VRR in cysts $>15 \mathrm{~mL}$ ( ref. $^{21}$ ). By contrast, Bennedbaek and Hegedüs $(n=33)$ were more successful at treating small cysts; there was no difference in the outcome between pure and complex cysts identified by ultrasound ${ }^{5}$. Similarly, Yasuda et al. $(n=61)$ and Kim YJ et al. $(n=217)$ showed a higher success rate and fewer recurrences for cysts $<10 \mathrm{~mL}$ (ref. ${ }^{12,20}$ ). Cho et al. found a correlation between the total amount of injected ethanol and the VRR, irrespective of whether the cyst was pure 


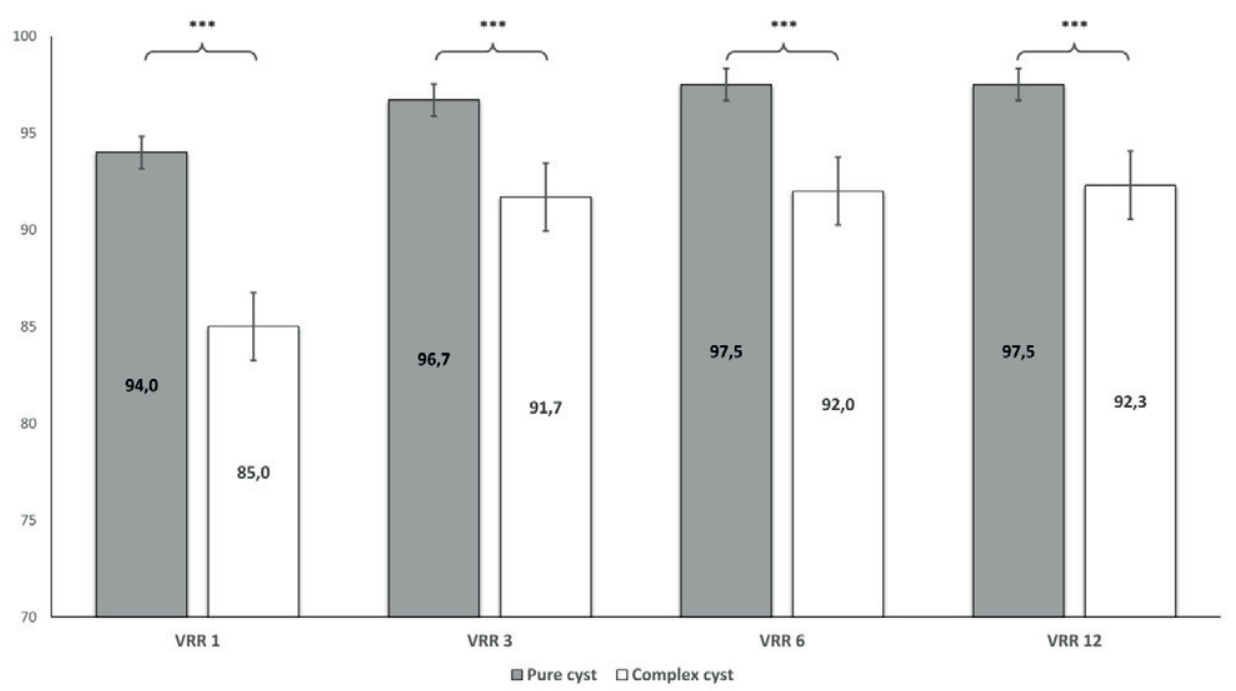

Fig. 4. Comparison of VRRs of complex and pure cysts at different months of follow up. Volume Reduction Rate (VRR) was calculated as follows: VRR (\%) = initial cyst volume - final cyst volume / initial cyst volume $\times 100$. VRR 1 - after one month, VRR 3 - after 3 months, VRR 6 - after 6 months, VRR after 12 months of follow up. Level of difference $* * * \sim P<0.001$.

Table 1. US-PEIT of thyroid cysts study: results for the entire cohort, three subgroups by cyst volume and two subgroups by character of the cystic component.

\begin{tabular}{|c|c|c|c|c|c|c|}
\hline $\begin{array}{l}\text { Cyst/number } \\
\text { F/M }\end{array}$ & $\begin{array}{c}\text { Total } \\
\text { cysts/200 } \\
157 \mathrm{~F} / 43 \mathrm{M}\end{array}$ & $\begin{array}{c}\text { Small } \\
\text { cysts/112 } \\
91 \mathrm{~F} / 21 \mathrm{M}\end{array}$ & $\begin{array}{c}\text { Medium } \\
\text { cysts/67 } \\
52 \mathrm{~F} / 15 \mathrm{M}\end{array}$ & $\begin{array}{c}\text { Large } \\
\text { cysts/21 } \\
14 \mathrm{~F} / 7 \mathrm{M}\end{array}$ & $\begin{array}{c}\text { Pure } \\
\text { cysts/49 } \\
39 \mathrm{~F} / 10 \mathrm{M}\end{array}$ & $\begin{array}{c}\text { Complex } \\
\text { cysts/151 } \\
118 \mathrm{~F} / 33 \mathrm{M}\end{array}$ \\
\hline Age (y) & $\begin{array}{c}49 \\
{[38-67]}\end{array}$ & $\begin{array}{c}47 \\
{[38-66]}\end{array}$ & $\begin{array}{c}50 \\
{[37-64]}\end{array}$ & $\begin{array}{c}63 \\
{[42-74.0]}\end{array}$ & $\begin{array}{c}43 \\
{[35-59]}\end{array}$ & $\begin{array}{c}50 \\
{[39-68]}\end{array}$ \\
\hline $\begin{array}{l}\text { Initial cyst } \\
\text { volume (mL) }\end{array}$ & $\begin{array}{c}8.5 \\
{[5.5-16.0]}\end{array}$ & $\begin{array}{c}6.0 \\
{[5.0-7.0]}\end{array}$ & $\begin{array}{c}15.0 \\
{[12.0-20.0]}\end{array}$ & $\begin{array}{c}43.0 \\
{[39.0-70.0]}\end{array}$ & $\begin{array}{c}7.0 \\
{[5.0-15.0]}\end{array}$ & $\begin{array}{c}9.0 \\
{[6.0-16.0]}\end{array}$ \\
\hline $\begin{array}{l}\text { VRR (\%) } \\
\text { at } 1 \text { month }\end{array}$ & $\begin{array}{c}88.5 \\
{[78.6-94.0]}\end{array}$ & $\begin{array}{c}84.5 \\
{[77.3-93.3]}\end{array}$ & $\begin{array}{c}88.6 \\
{[77.3-94.7]}\end{array}$ & $\begin{array}{c}94.2 \\
{[88.8-97.4]}\end{array}$ & $\begin{array}{c}94.0 \\
{[90.0-97.0]}\end{array}$ & $\begin{array}{c}85.0 \\
{[75.7-91.9] * * *}\end{array}$ \\
\hline $\begin{array}{l}\text { VRR (\%) } \\
\text { at } 3 \text { months }\end{array}$ & $\begin{array}{c}92.6 \\
{[85.0-96.7]}\end{array}$ & $\begin{array}{c}92.0 \\
{[83.7-96.0]}\end{array}$ & $\begin{array}{c}92.6 \\
{[85.5-97.0]}\end{array}$ & $\begin{array}{c}95.8 \\
{[93.0-98.2]}\end{array}$ & $\begin{array}{c}96.7 \\
{[94.6-98.0]}\end{array}$ & $\begin{array}{c}91.7 \\
{[81.3-95.3]^{* * *}}\end{array}$ \\
\hline $\begin{array}{l}\text { VRR (\%) } \\
\text { at } 6 \text { months }\end{array}$ & $\begin{array}{c}94.7 \\
{[86.5-97.5]}\end{array}$ & $\begin{array}{c}94.0 \\
{[85.4-96.8]}\end{array}$ & $\begin{array}{c}94.6 \\
{[86.4-98.2]}\end{array}$ & $\begin{array}{c}96.7 \\
{[94.1-99.0]}\end{array}$ & $\begin{array}{c}97.5 \\
{[95.0-98.6]}\end{array}$ & $\begin{array}{c}92.0 \\
{[83.3-96.7]^{* * *}}\end{array}$ \\
\hline $\begin{array}{l}\text { VRR (\%) } \\
\text { at } 12 \text { months }\end{array}$ & $\begin{array}{c}95.0 \\
{[86.7-98.0]}\end{array}$ & $\begin{array}{c}94.5 \\
{[85.7-97.5]}\end{array}$ & $\begin{array}{c}94.8 \\
{[86.4-98.3]}\end{array}$ & $\begin{array}{c}98.2 \\
{[94.1-99.0]}\end{array}$ & $\begin{array}{c}97.5 \\
{[95.5-98.7]}\end{array}$ & $\begin{array}{c}92.3 \\
{[83.3-96.7]^{* * *}}\end{array}$ \\
\hline $\begin{array}{l}\text { Final cyst } \\
\text { volume }(\mathrm{mL})\end{array}$ & $\begin{array}{c}0.5 \\
{[0.2-1.3]}\end{array}$ & $\begin{array}{c}0.3 \\
{[0.1-0.8]^{\mathrm{c}}}\end{array}$ & $\begin{array}{c}0.9 \\
{[0.3-2.0]}\end{array}$ & $\begin{array}{c}1.3 \\
{[0.6-2.5]^{\mathrm{a}}}\end{array}$ & $\begin{array}{c}0.2 \\
{[0.1-0.4]}\end{array}$ & $\begin{array}{c}0.7 \\
{[0.2-1.5]^{* * *}}\end{array}$ \\
\hline US-PEIT $\times$ & $\begin{array}{c}1.0 \\
{[1.0-2.0]}\end{array}$ & $\begin{array}{c}1.0 \\
{[1.0-2.0]^{\mathrm{b}, \mathrm{c}}}\end{array}$ & $\begin{array}{c}2.0 \\
{[1.0-2.0]^{\mathrm{a}, \mathrm{c}}}\end{array}$ & $\begin{array}{c}3.0 \\
{[2.0-3.0]^{\mathrm{a}, \mathrm{b}}}\end{array}$ & $\begin{array}{c}1.0 \\
{[1.0-2.0]}\end{array}$ & $\begin{array}{c}2.0 \\
{[1.0-2.0]^{* *}}\end{array}$ \\
\hline Ethanol (mL) & $\begin{array}{c}2.0 \\
{[1.0-3.0]}\end{array}$ & $\begin{array}{c}1.0 \\
{[1.0-2.0]^{\mathrm{b}, \mathrm{c}}}\end{array}$ & $\begin{array}{c}3.0 \\
{[2.0-4.0]^{\mathrm{a}}}\end{array}$ & $\begin{array}{c}8.0 \\
{[5.0-10.0]^{\mathrm{a}}}\end{array}$ & $\begin{array}{c}1.0 \\
{[1.0-3.0]}\end{array}$ & $\begin{array}{c}2.0 \\
{[1.0-3.0]^{*}}\end{array}$ \\
\hline $\begin{array}{l}\text { Ethanol vs. initial } \\
\text { cyst volume (\%) }\end{array}$ & $\begin{array}{c}20.0 \\
{[16.7-28.6]}\end{array}$ & $\begin{array}{c}25.0 \\
{[20.0-33.3]}\end{array}$ & $\begin{array}{c}18.8 \\
{[15.4-25.0]}\end{array}$ & $\begin{array}{c}15.9 \\
{[9.1-20.9]}\end{array}$ & $\begin{array}{c}20.0 \\
{[13.3-20.0]}\end{array}$ & $\begin{array}{c}22.7 \\
{[16.7-33.3]^{* *}}\end{array}$ \\
\hline
\end{tabular}

F - females, M - males, initial cyst volume - volume of the cyst before sclerotherapy, VRR - volume reduction rate at intervals after the completion of sclerotherapy, final cyst volume - volume of the cyst at 12 months after the completion of sclerotherapy, US-PEIT $\times$ - the mean number of sclerotherapy sessions per cyst, ethanol - the total amount of instilled ethanol per cyst, ethanol vs. initial cyst volume - proportion of the total amount of ethanol to the initial cyst volume

Significant difference $P<0.05$ at least $-{ }^{\mathrm{a}} \mathrm{v}$. small cysts ${ }^{\mathrm{b}}$ vs. medium cysts; ${ }^{\mathrm{c}} \mathrm{vs}$. large cysts.

$* \sim P<0.05, * * \sim P<0.01, * * * \sim P<0.001 \ldots$ statistical significance level of difference 
or complex ${ }^{6}$. A study by Raggiunti et al. $(n=109)$ showed a statistically significant correlation between the initial cyst volume and the number of US-PEIT sessions ${ }^{22}$. The present study showed no statistically significant differences in the VRR between cyst volume subgroups. Medium-sized and large cysts required more ethanol and US-PEIT sessions than small cysts (not statistically significant). At 12 months, the final VRR was not statistically different for all cyst volumes. Consistently with other studies, no significant correlations were found with age or gender ${ }^{5,22}$.

We performed multiple regression analysis and found the presence of complex cyst to be an independent predictor of treatment success. Apropos VRR, the overall value was $95.0 \%$; VRR of pure and complex cysts differed statistically significantly $(97.5 \%$ and $92.3 \%, P<0.001)$.

The latter were less successfully treated, in particular with the first ethanol injection. Similar results were reported by Basu et al. ( $n=60$; pure/complex cysts $42 / 18$ ), with the VRR being $92.8 \%$ for pure cysts and only $44.4 \%$ for complex cysts. Significantly better treatment response was observed in pure cysts $(P<0.001)$ while complex cysts were associated with higher recurrence rates and need for repeated treatment ${ }^{23}$. When treating complex, mediumsized and large cysts, more US-PEIT sessions and ethanol were needed. Additionally, higher amounts of ethanol relative to the initial cyst volume were needed to treat complex cysts.

Generally, there are no exact recommendations regarding the amount of ethanol injected during a single US-PEIT session, intervals between US-PEIT sessions or use of local anesthesia. In particular, considerably different amounts of ethanol have been reported by various authors. In the present study, small amounts of ethanol were used initially due to the concerns for potential local side effects. Our first experiences with US-PEIT were gained from small and medium-sized cysts $(n=33)$ successfully treated with ethanol amounts equal to $22.7 \pm 7.9 \%$ of the initial cyst volume ${ }^{11}$. Later, large cysts $(\geq 31 \mathrm{~mL})$ were added to the cohort as well. To achieve therapeutic success in both large cysts $(n=21)$ and the entire cohort $(n=200)$, relatively small amounts of ethanol were needed, corresponding to $15.9 \%$ [9.1-20.9] resp. $20.0 \%$ [16.7-28.6] of the initial cyst volume. Similarly, other studies showed successful US-PEIT with small ethanol amounts. Reverter et al. reported injecting a maximum of $2 \mathrm{~mL}$ per one session ( $n=30$, mean initial cyst volume $15.5 \mathrm{~mL}, 1-6$ ethanol injections, VRR at 12 months $85.9 \%$ ) (ref. ${ }^{21}$ ). Raggiunti et al. used ethanol amounts equal to $25 \%$ of the cyst volume per one injection ${ }^{22}$. Bennedbaek and Hegedüs instilled ethanol corresponding to $25-50 \%$ of the aspirated fluid (no more than $10 \mathrm{~mL}$ ) at monthly intervals, performing 1-3 US-PEIT sessions per patient ${ }^{5}$. The amounts of ethanol injected by Kim YJ et al. were $\approx 50 \%$ of the aspirated fluid $^{20}$. By contrast, Cho et al. injected large amounts of ethanol, equal to $40-100 \%$ of the fluid drawn from the cyst $^{6}$. Also, Kim DW et al. applied ethanol in amounts corresponding to as much as $100 \%$ of the aspirated fluid (up to $20 \mathrm{~mL}$ ); they used $30 \mathrm{~mL}$ of ethanol in one case of an extremely large cyst (135 mL) ( ref. $\left.^{7}\right)$. At 2-month intervals, Lee and Ahn injected alcohol amounts equal to approximately $40-100 \%$ of the aspirated fluid ${ }^{12}$. Valcavi and Frasoldati used ethanol in amounts comparable to $50-70 \%$ of the fluid removed from the cyst ${ }^{14}$.

Treatment complications and adverse events result from ethanol leaking into the adjacent tissues. After the procedure, most patients report mild transient pain at the site of injection that radiates to the neck, chin and ears. The incidence varies across studies, ranging from $2.5 \%$ to $30 \%$ and, in large cysts, to as many as $70 \%$ of patients $^{7,16,20}$. Cho et al. noted local pain after injection in 2 out of 22 patients (9\%) (ref. $\left.{ }^{6}\right)$. In a study by Bennedbaek and Hegedüs, 7 out of 33 patients (21\%) had local pain lasting for $10 \mathrm{~min}$ to $1 \mathrm{~h}$ and one patient reported transient dysphonia for $1 \mathrm{~h}$ (ref. $\left.{ }^{5}\right)$. Although local anesthesia is not required prior to US-PEIT, it was administered, for example, by Kim YJ et al. or Raggiunti et al. ${ }^{20,22}$. In a study by Kim YJ et al., 5 out of 209 patients (1.7\%) experienced pain immediately after the procedure that subsided rapidly within minutes but no other complications were observed $^{20}$. In a study of 110 patients by Raggiunti et al., two suffered from transient dysphonia ${ }^{22}$. In the largest cohort of 432 patients with complex cysts, Lee and Ahn reported transient local pain in 32 individuals $(7.9 \%)$ and transient unilateral vocal fold paralysis in only 3 patients $(0.7 \%)$ (ref. $\left.{ }^{12}\right)$. Very rarely, transient thyrotoxicosis may occur ${ }^{15}$.

The present study has shown that it is beneficial to follow up patients regularly beyond the standard monitoring interval (12 months). Most of our patients opted for an ultrasound monitoring at yearly intervals after the 12-month period from the completion of US-PEIT; so far, the longest follow-up has been 11 years. In three patients originally treated for complex medium-sized cysts (3/200; $1.5 \%$ ) we observed recurrence (another new cystic cavity $>3 \mathrm{~mL}$ ) in a period longer than 12 months. In each case, the cystic cavity that recurred was smaller than the original one and was treated by another US-PEIT session, without a need for surgery.

For successful US-PEIT of thyroid cysts of all sizes, it is sufficient to use relatively small total amounts of ethanol, corresponding to $\approx 20 \%$ of the initial cyst volume.

\section{CONCLUSION}

We assessed that the small amount of ethanol is sufficient to necrotize the collapsed cystic wall and possess lower risk of ethanol leakage into surrounding tissues. Therefore, US-PEIT for thyroid cysts with relatively small total amounts of ethanol is safe and successful alternative to surgery. Carefully selected patients warranted by relevant ultrasound findings should benefit from this method.

Acknowledgment: Supported by MH CZ DRO (FNOl, 00098892) - 87-62.

Author contributions: MH: US-PEIT of thyroid cyst $\mathrm{n}=200$, manuscript preparation, literature search; DK: data analysis; JS: manuscript preparation, final approval; ZF: literature search, final approval. 
Conflict of interest statement: The authors state that there are no conflicts of interest regarding the publication of this article.

\section{REFERENCES}

1. Haugen BR, Sawka AM, Alexander EK, Bible KC, Caturegli P, Doherty GM, Mandel SJ, Morris JC, Nassar A, Pacini F, Schlumberger M, Schuff K, Sherman SI, Somerset H, Sosa JA, Steward DL, Wartofsky $\mathrm{L}$, Williams MD. American Thyroid Association Guidelines on the Management of Thyroid Nodules and Differentiated Thyroid Cancer Task Force Review and Recommendation on the Proposed Renaming of Encapsulated Follicular Variant Papillary Thyroid Carcinoma Without Invasion to Noninvasive Follicular Thyroid Neoplasm with Papillary-Like Nuclear Features. Thyroid 2017;27(4):481-3.

2. Sheppard MC, Franklyn JA. Management of the single thyroid nodule. Clin Endocrinol (Oxf) 1992;37(5):398-401.

3. Choi KU, Kim JY, Park DY, Lee CH, Sol MY, Han KT, Kim YG. Recommendations for the management of cystic thyroid nodules. ANZ J Surg 2005;75(7):537-41.

4. Moon WJ, Baek JH, Jung SL, Kim DW, Kim EK, Kim JY, Kwak JY, Lee JH, Lee JH, Lee YH, Na DG, Park JS, Park SW; Korean Society of Thyroid Radiology (KSThR); Korean Society of Radiology. Ultrasonography and the ultrasound-based management of thyroid nodules: consensus statement and recommendations. Korean J Radiol 2011;12(1):114.

5. Bennedbaek FN, Hegedüs L. Treatment of recurrent thyroid cysts with ethanol: a randomized double-blind controlled trial. J Clin Endocrinol Metab 2003;88(12):5773-7.

6. Cho YS, Lee HK, Ahn IM, Lim SM, Kim DH, Choi CG, Suh DC Sonographically guided ethanol sclerotherapy for benign thyroid cysts: results in 22 patients. AJR Am J Roentgenol 2000;174(1):213-6.

7. Kim DW, Rho MH, Kim HJ, Kwon JS, Sung YS, Lee SW. Percutaneous ethanol injection for benign cystic thyroid nodules: is aspiration of ethanol-mixed fluid advantageous? Am J Neuroradiol 2005;26(8):2122-7.

8. Sung JY, Baek JH, Kim YS, Jeong HJ, Kwak MS, Lee D, Moon WJ. Onestep ethanol ablation of viscous cystic thyroid nodules. AJR Am J Roentgenol 2008;191(6):1730-3.

9. Gharib H, Papini E, Valcavi R, Baskin HJ, Crescenzi A, Dottorini ME, Duick DS, Guglielmi R, Hamilton CR Jr, Zeiger MA, Zini M; AACE/ AME Task Force on Thyroid Nodules. American Association of Clinical Endocrinologists and Associazione Medici Endocrinologi medical guidelines for clinical practice for the diagnosis and management of thyroid nodules. Endocr Pract 2006;12(1):63-102.

10. Gharib H, Papini E, Paschke R, Duick DS, Valcavi R, Hegedüs L, Vitti P; AACE/AME/ETA Task Force on Thyroid Nodules. American Association of Clinical Endocrinologists, Associazione Medici
Endocrinologi, and EuropeanThyroid Association Medical Guidelines for Clinical Practice for the Diagnosis and Management of Thyroid Nodules. Endocr Pract 2010;16 Suppl 1:1-43.

11. Lee SJ, Ahn IM. Effectiveness of percutaneous ethanol injection therapy in benign nodular and cystic thyroid diseases: long-term follow-up experience. Endocr J 2005;52(4):455-62.

12. Yasuda K, Ozaki O, Sugino K, Yamashita T, Toshima K, Ito K, Harada $\mathrm{T}$. Treatment of cystic lesions of the thyroid by ethanol instillation. World J Surg 1992;16(5):958-61.

13. Verde G, Papini E, Pacella CM, Gallotti C, Delpiano S, Strada S, Fabbrin R, Bizzarri G, Rinaldi R, Panunzi C. Ultrasound guided percutaneous ethanol injection in the treatment of cystic thyroid nodules. Clin Endocrinol (Oxf) 1994;41(6):719-24.

14. Valcavi R, Frasoldati A. Ultrasound-guided percutaneous ethanol injection therapy in thyroid cystic nodules. Endocr Pract 2004;10(3):269-75.

15. Antonelli A, Campatelli A, Di Vito A, Alberti B, Baldi V, Salvioni G, Fallahi P, Baschieri L. Comparison between ethanol sclerotherapy and emptying with injection of saline in treatment of thyroid cysts. The Clinical investigator 1994;72(12):971-4.

16. Zingrillo M, Torlontano M, Ghiggi MR, D'Aloiso L, Nirchio V, Bisceglia M, Liuzzi A. Percutaneous ethanol injection of large thyroid cystic nodules. Thyroid 1996;6(5):403-8.

17. Zingrillo $M$, Torlontano $M$, Chiarella R, Ghiggi MR, Nirchio V, Bisceglia $M$, Trischitta V. Percutaneous Ethanol Injection May be a Definitive Treatment for Symptomatic Thyroid Cystic Nodules not Treatable by Surgery: Five-Year Follow-Up Study. Thyroid 1999;9(8):763-7.

18. Del Prete $S$, Caraglia M, Russo D, Vitale G, Giuberti G, Marra M, D'Alessandro AM, Lupoli G, Addeo R, Facchini G, Rossiello R, Abbruzzese A, Capasso E. Percutaneous ethanol injection efficacy in the treatment of large symptomatic thyroid cystic nodules: tenyear follow-up of a large series. Thyroid 2002;12(9):815-21.

19. Monzani F, Lippi F, Goletti O, Del Guerra P, Caraccio N, Lippolis PV, Baschieri L, Pinchera A. Percutaneous aspiration and ethanol sclerotherapy for thyroid cysts. J Clin Endocrinol Metab 1994;78(3):800-2.

20. Kim YJ, Baek JH, Ha EJ, Lim HK, Lee JH, Sung JY, Kim JK, Kim TY, Kim WB, Shong YK. Cystic versus predominantly cystic thyroid nodules: efficacy of ethanol ablation and analysis of related factors. Eur Radiol 2012;22(7):1573-8.

21. Reverter JL, Alonso N, Avila M, Lucas A, Mauricio D, Puig-Domingo M. Evaluation of efficacy, safety, pain perception and health-related quality of life of percutaneous ethanol injection as first-line treatment in symptomatic thyroid cysts. BMC Endocr Disord 2015;15:73.

22. Raggiunti B, Fiore G, Mongia A, Balducci G, Ballone E, Capone F. A 7-year follow-up of patients with thyroid cysts and pseudocysts treated with percutaneous ethanol injection: volume change and cost analysis. J Ultrasound 2009;12(3):107-11.

23. Basu N, Dutta D, Maisnam I, Basu S, Ghosh S, Chowdhury S, Mukhopadhyay S. Percutaneous ethanol ablation in managing predominantly cystic thyroid nodules: An eastern India perspective. Indian J Endocrinol Metab 2014;18(5):662-8. 